\title{
Optimization of Hapten-Peptide Labeling for Pretargeted ImmunoPET of Bispecific Antibody Using Generator-Produced ${ }^{68} \mathrm{Ga}$
}

\author{
Habibe Karacay ${ }^{1}$, Robert M. Sharkey ${ }^{1}$, William J. McBride ${ }^{2}$, Edmund A. Rossi ${ }^{3}$, Chien-Hsing Chang 2,3 , \\ and David M. Goldenberg ${ }^{1}$ \\ ${ }^{1}$ Center for Molecular Medicine and Immunology and the Garden State Cancer Center, Belleville, New Jersey; ${ }^{2}$ Immunomedics, Inc., \\ Morris Plains, New Jersey; and ${ }^{3}$ IBC Pharmaceuticals, Inc., Morris Plains, New Jersey
}

Bispecific antibody pretargeting is highly sensitive and specific
for cancer detection by PET. In this study, the preparation of
a high-specific-activity ${ }^{68} \mathrm{Ga}$-labeled hapten-peptide, IMP288,
was evaluated. Methods: IMP288 (DOTA-D-Tyr-D-Lys(hista-
mine-succinyl-glycine [HSG])-D-glu-D-Lys(HSG)-NH${ }_{2}$ ) was added
to buffered ${ }^{68} \mathrm{Ga}$ and then heated in boiling water and purified
on a reversed-phase cartridge. Tumor-bearing nude mice
were used for biodistribution and tumor localization studies.
Results: ${ }^{68} \mathrm{Ga-IMP288}$ was prepared at a starting specific
activity up to $1.78 \mathrm{GBq} / \mathrm{nmol}$, with final yields of $0.74 \mathrm{GBq} / \mathrm{nmol}$
(decay-corrected) and less than $1 \%$ unbound ${ }^{68} \mathrm{Ga}$. Purification
was essential to remove unbound ${ }^{8} \mathrm{Ga}$ and ${ }^{68} \mathrm{Ge}$ breakthrough.
Pretargeted animals showed a high ${ }^{68} \mathrm{Ga}-\mathrm{IMP} 288$ uptake
(27.5 \pm 5.8 percentage injected dose per gram), with ratios
of $13.6 \pm 4.8,66.8 \pm 14.5$, and $325.9 \pm 61.9$ for the kidneys,
liver, and blood, respectively, at $1.5 \mathrm{~h}$ after peptide injection.
Conclusion: High-specific-activity labeling of DOTA-hapten-
peptide was obtained from the ${ }^{68} \mathrm{Ga} /{ }^{68} \mathrm{Ge}$ generator for
approximately $1 \mathrm{y}$, yielding products suitable for immunoPET.

Key Words: bispecific antibody; pretargeting; ${ }^{68} \mathrm{Ga} ;{ }^{68} \mathrm{Ge} /{ }^{68} \mathrm{Ga}$ generator

J Nucl Med 2011; 52:555-559

DOI: 10.2967/jnumed.110.083568

$\mathbf{T}$ he PET radionuclide ${ }^{68} \mathrm{Ga}$ can be obtained from commercially available ${ }^{68} \mathrm{Ge}$ generators with no carrier added, allowing compounds to be prepared at high specific activity. The half-life of ${ }^{68} \mathrm{Ge}(270.8 \mathrm{~d})$ allows the generator to be used for an extended period, which reduces the unit-dose cost, and the half-life of ${ }^{68} \mathrm{Ga}(67.6 \mathrm{~min})$ is suitable for rapidly clearing molecules, such as peptides. Interest in ${ }^{68} \mathrm{Ga}$-labeled compounds has been growing over the past $10 \mathrm{y}$, with promising initial clinical results $(1-11)$.

Received Sep. 22, 2010; revision accepted Dec. 17, 2010.

For correspondence or reprints contact: Robert M. Sharkey, Center for Molecular Medicine and Immunology and the Garden State Cancer Center, 520 Belleville Ave., Belleville, NJ 07109.

E-mail: rmsharkey@gscancer.org

COPYRIGHT @ 2011 by the Society of Nuclear Medicine, Inc.
We are interested in using a small radiolabeled haptenpeptide as part of a bispecific antibody (bsmAb) pretargeting procedure for PET. Previous studies reported high tumor uptake with minimal accretion in normal tissues, producing targeting superior to that of directly radiolabeled antibody fragments and greater sensitivity and specificity than ${ }^{18}$ F-FDG $(12-14)$. Like directly radiolabeled peptides, the hapten-peptide used in pretargeting would benefit from high-specific-activity labeling. Thus, the main objective of the study was to evaluate the suitability of ${ }^{68} \mathrm{Ga}$ for pretargeting.

\section{MATERIALS AND METHODS}

\section{Reagents}

Humanized tri-Fab bsmAb TF2 and IMP288 (DOTA-D-TyrD-Lys(histamine-succinyl-glycine [HSG]-D-Glu-D-Lys(HSG)- $\mathrm{NH}_{2}$ ) were described previously $(12,15)$. A $1.3 \mathrm{mM}$ stock solution of IMP288 was diluted to $6.5 \times 10^{-5} \mathrm{M}$ in $1 \mathrm{M} \mathrm{N}$-(2-hydroxyethyl) piperazine- $N^{\prime}$-(2-ethanesulfonic acid) (HEPES), pH 6.9, and stored at $-20^{\circ} \mathrm{C}$.

\section{${ }^{68} \mathrm{Ga}$ Generator}

The IGG-100, $1.85-\mathrm{GBq}(50-\mathrm{mCi}){ }^{68} \mathrm{Ga}$ generator was purchased from Eckert-Ziegler Isotope Products Eurotope $\mathrm{GmbH}$ and eluted according to the manufacturer's recommendations, using $0.1 \mathrm{M} \mathrm{HCl}$. Three fractions $(1.5,1.0$, and $2.5 \mathrm{~mL})$ were isolated, with fraction 2 containing the highest concentration of ${ }^{68} \mathrm{Ga}$.

Within $2-17 \mathrm{~d}$ of the ${ }^{68} \mathrm{Ga}$ elution, aliquots of fraction 2 and a sample of the radiolabeled product before and after purification were counted in an open window using a Wizard 3" automatic $\gamma$-counter (Perkin Elmer). To approximate the amount of the ${ }^{68} \mathrm{Ge}$ counts in fraction 2 , we assumed $100 \%$ counting efficiency and expressed the activity as Becquerels of ${ }^{68} \mathrm{Ge} / 37 \mathrm{MBq}$ of ${ }^{68} \mathrm{Ga}$. The ${ }^{68} \mathrm{Ge}$ counts in the labeled product were normalized as a percentage of the activity in fraction 2 used to prepare the labeled product.

\section{Radiolabeling}

IMP288 was radiolabeled with ${ }^{111} \mathrm{InCl}_{3}$, according to methods published previously (specific activity, 36.8 MBq/nmol [0.995 $\mathrm{mCi} / \mathrm{nmol}] ;<3 \%$ unbound by instant thin-layer chromatography) (12).

The ${ }^{68} \mathrm{Ga}$-labeling procedure was modeled after that reported previously, with some modifications (13). IMP288 was added to 
all or a portion of fraction 2, along with 1.0 M HEPES, pH 6.9. After being heated in a boiling water bath for $12 \mathrm{~min}$, the vial was cooled in an ice bath to room temperature, and then $0.1 \mathrm{M}$ ethylenediaminetetraacetic acid, $\mathrm{pH} 5.5$, was added to a final concentration of $5 \mathrm{mM}$. The mixture was transferred to a reversed-phase polymeric-sorbent packed, 1-mL Oasis HLB cartridge for purification (Waters). After it was washed with three $1.0-\mathrm{mL}$ aliquots of water, the product was eluted with two $200-\mu \mathrm{L}$ aliquots of water:ethanol (1:1) into a vial containing $50 \mu \mathrm{L}$ of ascorbic acid (300 mg/mL).

The peptide concentration ranged from 400 to $650 \mathrm{nM}$ and from 200 to $250 \mathrm{nM}$ for preparations that started with a specific activity of 0.888 and $1.776 \mathrm{GBq} / \mathrm{nmol}$, respectively (116- and 56-fold molar excess to the ${ }^{68} \mathrm{Ga}$ activity, respectively). Final specific activity assumed full recovery of IMP288 from the HLB cartridge.

Unbound ${ }^{68} \mathrm{Ga}$ was determined by reverse-phase HPLC (RPHPLC) (Nova-Pak C18, $4 \mu \mathrm{m}, 8 \times 100 \mu \mathrm{m}$ Radial-Pak; Waters).

Additional details can be found in the supplemental data (available online only at http://jnm.snmjournals.org).

\section{Animal Studies}

Nude mice bearing subcutaneous implants of human colonic cancer cell lines were given intravenous injections of the radiolabeled product. Specific information regarding the doses administered and methods are provided in the "Results" section and supplemental data.

\section{RESULTS}

\section{Generator Elution}

Over a period of $350 \mathrm{~d}$ from generator calibration, $79.9 \% \pm 3.1 \%$ of the expected ${ }^{68} \mathrm{Ga}$ activity was accounted for in the total elution volume (Fig. 1). Fraction $2(1 \mathrm{~mL})$ contained $63 \%-83 \%$ of the total eluted activity. An approximation of ${ }^{68} \mathrm{Ge}$ activity, based on an estimated counting efficiency of $100 \%$, revealed that $0.05-0.22 \mathrm{~Bq}$ of ${ }^{68} \mathrm{Ge} /$ $\mathrm{MBq}$ of ${ }^{68} \mathrm{Ga}$ was present in fraction 2, except for 2 instances in which it was 0.64 and $0.49 \mathrm{~Bq}$ of ${ }^{68} \mathrm{Ge} / \mathrm{MBq}$ of ${ }^{68} \mathrm{Ga}$ between days 160 and 350. Assays performed on samples taken before and after purification indicated the HLB purification assisted in the removal of unbound ${ }^{68} \mathrm{Ga}$ but also of ${ }^{68} \mathrm{Ge}$. For example, most often ${ }^{68} \mathrm{Ge}$ was not detected in aliquots of purified ${ }^{68} \mathrm{Ga}-\mathrm{IMP} 288$, but when present, more than $95 \%$ of the ${ }^{68} \mathrm{Ge}$ in the fraction 2 used for the labeling had been removed.

\section{${ }^{68}$ Ga-IMP288 Radiolabeling}

${ }^{68} \mathrm{Ga}$-IMP288 preparation was completed within 30 $40 \mathrm{~min}$. Variable product recovery was encountered when following the procedure of Schoffelen et al. (13), suggesting that colloidal forms of gallium were formed. Three labeling procedures were performed using IMP288 $(0.444$ $\mathrm{GBq} / \mathrm{nmol}$ ) with HEPES added at one half, one quarter, or one eighth of the ${ }^{68} \mathrm{Ga}$ volume. Mock mixtures found that the $\mathrm{pH}$ was 4.6 at one half, 3.7 at one quarter, and 3.1 at one eighth of the volume. Analysis without HLB purification showed that each label had approximately $0.9 \%$ unbound ${ }^{68} \mathrm{Ga}$ by RP-HPLC, but the RP-HPLC recoveries were $60 \%$, $74 \%$, and $87 \%$, respectively, suggesting colloid formation at a higher $\mathrm{pH}$. Therefore, all subsequent labeling proce-

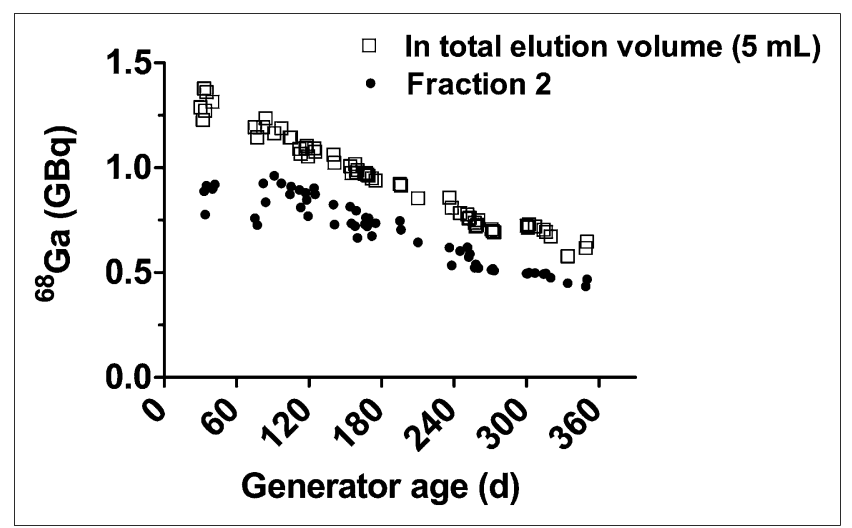

FIGURE 1. ${ }^{68} \mathrm{Ga}$ generator was eluted over $350 \mathrm{~d}$ with $0.1 \mathrm{M} \mathrm{HCl}$ in 3 fractions, starting $28 \mathrm{~d}$ after its calibration date. Activity in 1-mL fraction 2 and total in all fractions are shown.

dures were performed with HEPES buffer at one eighth of the ${ }^{68} \mathrm{Ga}$ volume.

The starting specific activity was increased to as high as $1.776 \mathrm{GBq} / \mathrm{nmol}$ using peptide concentrations ranging from approximately 200 to approximately $650 \mathrm{nM}$. High specific activity could be achieved when the generator was $350 \mathrm{~d}$ old using a starting ratio of $0.888 \mathrm{GBq} / \mathrm{nmol}$ (unbound ${ }^{68} \mathrm{Ga}, \sim 1 \%$ ).

Initially, ascorbic acid was added only to the HLBpurified product, but later several products were prepared by adding ascorbic acid to the reaction mixture before heating at a final concentration of $6.7 \mathrm{mg} / \mathrm{mL}$. This step improved recovery without compromising product quality (e.g., at initial specific activity of $0.88 \mathrm{GBq} / \mathrm{nmol},{ }^{68} \mathrm{Ga}-$ IMP288 recovery improved from 59.1\% $\pm 8.8 \%[n=$ 11] to $70.4 \% \pm 16.8 \%[n=6])$. A mock-labeling mixture showed that the addition of ascorbic acid had little effect on the $\mathrm{pH}$. Cenolate (Hospira Worldwide, Inc.), pH 6.18, ascorbic acid for human use, could not be added during radiolabeling, presumably because of the presence of excessive amounts of aluminum or the higher $\mathrm{pH}$.

Seven products, all including ascorbic acid in the reaction mixture, were prepared at the initial specific activity of $1.7 \mathrm{GBq} / \mathrm{nmol}$. The overall recovery of the purified product without decay correction was $38.3 \% \pm$ $8.9 \%(54.1 \% \pm 10.5 \%$ decay-corrected; starting activity was $407-444 \mathrm{MBq}$ ). These 7 labeled products were stable for $2 \mathrm{~h}$ at room temperature (i.e., RP-HPLC indicated no change in unbound or the molecular character of IMP288, and size-exclusion HPLC showed that HSG-binding was retained) (data not shown).

\section{Biodistribution}

One animal injected with ${ }^{68} \mathrm{Ga}$-IMP288 before HLB purification (3.5\% unbound by RP-HPLC and 14\% colloidal ${ }^{68} \mathrm{Ga}$, as indicated by the activity retained on the RPHPLC) had 14.1 percentage injected dose per gram $(\% \mathrm{ID} / \mathrm{g})$, $4.5 \% \mathrm{ID} / \mathrm{g}$, and $2.1 \% \mathrm{ID} / \mathrm{g}$, respectively, in the liver, spleen, 


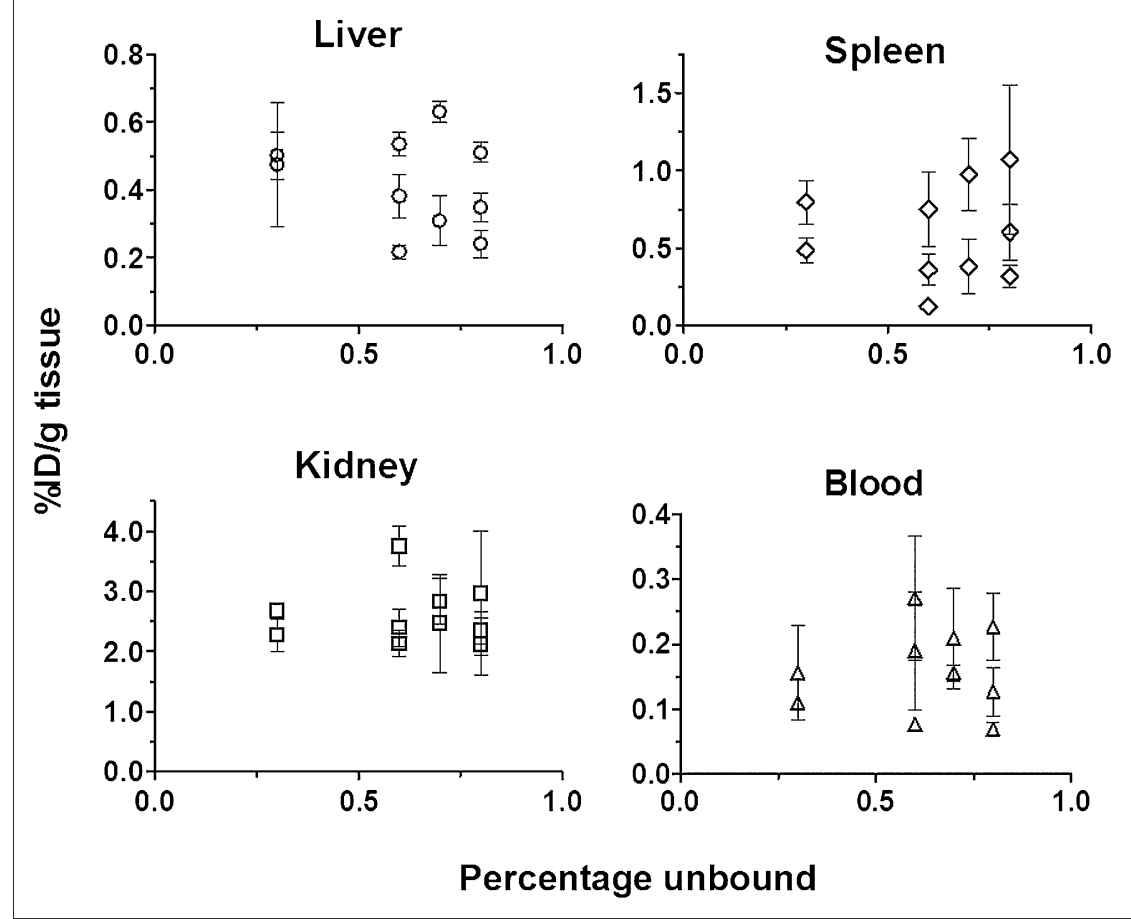

FIGURE 2. Evaluation of ${ }^{68} \mathrm{Ga}-\mathrm{IMP} 288$ tissue uptake in 10 separate studies. Each study consisted of groups of 2-5 mice that were given 25 pmole (7.77-11.1 MBq [210$300 \mu \mathrm{Ci}])$ of ${ }^{68} \mathrm{Ga}-\mathrm{IMP} 288$ and necropsied $1 \mathrm{~h}$ later. and bone at $1 \mathrm{~h}$ after injection. Most of the purified products had less than $1 \%$ unbound ${ }^{68} \mathrm{Ga}$ by RP-HPLC, and in 10 separate studies with purified product prepared without ascorbic acid, uptake in the liver, spleen, kidneys, and blood at $1 \mathrm{~h}$ after injection averaged $0.42 \pm 0.05,0.59 \pm 0.13$, $2.60 \pm 0.29$, and $0.16 \pm 0.04 \% \mathrm{ID} / \mathrm{g}$, respectively (Fig. 2). Thus, purification was considered essential to minimize normal-tissue uptake.

TF2 anti-CEACAM5 pretargeting was assessed in mice bearing either subcutaneous LS 174T or HT-29 xenografts. A TF2 dose-finding study was performed with a fixed amount of ${ }^{111} \mathrm{In}$-IMP288 given at $16 \mathrm{~h}$ after the TF2 injec- tions, using 10:1, 20 or $25: 1$, and 40:1 TF2: ${ }^{111}$ In IMP288 mol ratios. In each model, 25:1 to 40:1 was preferred (Fig. 3).

Pretargeted ${ }^{68} \mathrm{Ga}-\mathrm{IMP} 288$ tumor uptake averaged $27.5 \pm$ $5.8 \% \mathrm{ID} / \mathrm{g}$ in LS 174T, with low tissue uptake providing high tumor-to-nontumor ratios at $1.5 \mathrm{~h}$ after injection (Table 1). ${ }^{68} \mathrm{Ga}$-IMP288 alone was $0.33 \pm 0.07 \% \mathrm{ID} / \mathrm{g}$. Tumor and tissue uptake of the ${ }^{68} \mathrm{Ga}$-IMP288 compared favorably to LS 174T-bearing animals that had been necropsied at $1.0 \mathrm{~h}$ after being given TF2-pretargeted ${ }^{111}$ In-IMP288; however, there was a suggestion that liver and spleen uptake was higher for the ${ }^{68} \mathrm{Ga}$ group $(P<0.05)$ and a suggestion of

TABLE 1

Tissue Uptake of ${ }^{68} \mathrm{Ga}-I M P 288$ in Mice Bearing Subcutaneous LS 174T Human Colon Cancer Xenografts

\begin{tabular}{lccc}
\hline \multicolumn{1}{c}{ Tissue } & TF2/68 Ga-IMP288 $(n=5)$ & ${ }^{68} \mathrm{Ga}-\mathrm{IMP} 288(\mathrm{no} \mathrm{TF2})(n=5)$ & TF2/111 In-IMP288 $(n=5)$ \\
\hline Tumor & $27.5 \pm 5.8$ & $0.33 \pm 0.07$ & $23.6 \pm 5.4$ \\
Tumor weight $(\mathrm{g})$ & $0.40 \pm 0.10$ & $1.11 \pm 0.37$ & $0.37 \pm 0.18$ \\
Liver & $0.41 \pm 0.03$ & $0.38 \pm 0.06$ & $0.11 \pm 0.03$ \\
Spleen & $0.62 \pm 0.24$ & $0.36 \pm 0.10$ & $0.13 \pm 0.02$ \\
Kidney & $2.08 \pm 0.25$ & $2.40 \pm 0.31$ & $2.99 \pm 0.79$ \\
Lung & $0.26 \pm 0.04$ & $0.22 \pm 0.04$ & $0.28 \pm 0.06$ \\
Blood & $0.09 \pm 0.01$ & $0.19 \pm 0.09$ & $0.09 \pm 0.02$ \\
Stomach & $0.07 \pm 0.09$ & $0.09 \pm 0.08$ & $0.22 \pm 0.17$ \\
Small intestine & $0.17 \pm 0.02$ & $0.22 \pm 0.10$ & $0.36 \pm 0.16$ \\
Large intestine & $0.20 \pm 0.36$ & $0.10 \pm 0.07$ & $0.14 \pm 0.11$ \\
Scapula & $0.06 \pm 0.02$ & $0.06 \pm 0.03$ & $0.19 \pm 0.17$
\end{tabular}

Tissue uptake $(\% \mathrm{ID} / \mathrm{g})$ data are mean $\pm \mathrm{SD}$. TF2 anti-CEACAM5 bsmAb $\left(100 \mu \mathrm{g}, 6.34 \times 10^{-10}\right.$ mol) was given intravenously; then, $16 \mathrm{~h}$ later, ${ }^{68} \mathrm{Ga}-I M P 288\left(2.53 \times 10^{-11} \mathrm{~mol}, 9.065 \mathrm{MBq}\right.$ [245 $\mu \mathrm{Ci}$; ; specific activity, $0.397 \mathrm{GBq} / \mathrm{nmol}$; prepared in absence of ascorbic acid) was given. Another group received only ${ }^{68} \mathrm{Ga}-\mathrm{IMP} 288\left(2.53 \times 10^{-11} \mathrm{~mol}, 9.99 \mathrm{MBq}[270 \mu \mathrm{Ci}]\right)$. Mice were necropsied $1.5 \mathrm{~h}$ after peptide injection. In separate study, mice were given TF2 $\left(100 \mu \mathrm{g}, 6.34 \times 10^{-10} \mathrm{~mol}\right)$ followed $16 \mathrm{~h}$ later by ${ }^{111} \mathrm{In}-\mathrm{IMP} 288\left(2.53 \times 10^{-11} \mathrm{~mol}, 0.925\right.$ $\mathrm{MBq}[25 \mu \mathrm{Ci}])$, and then were necropsied $1 \mathrm{~h}$ afterward. 


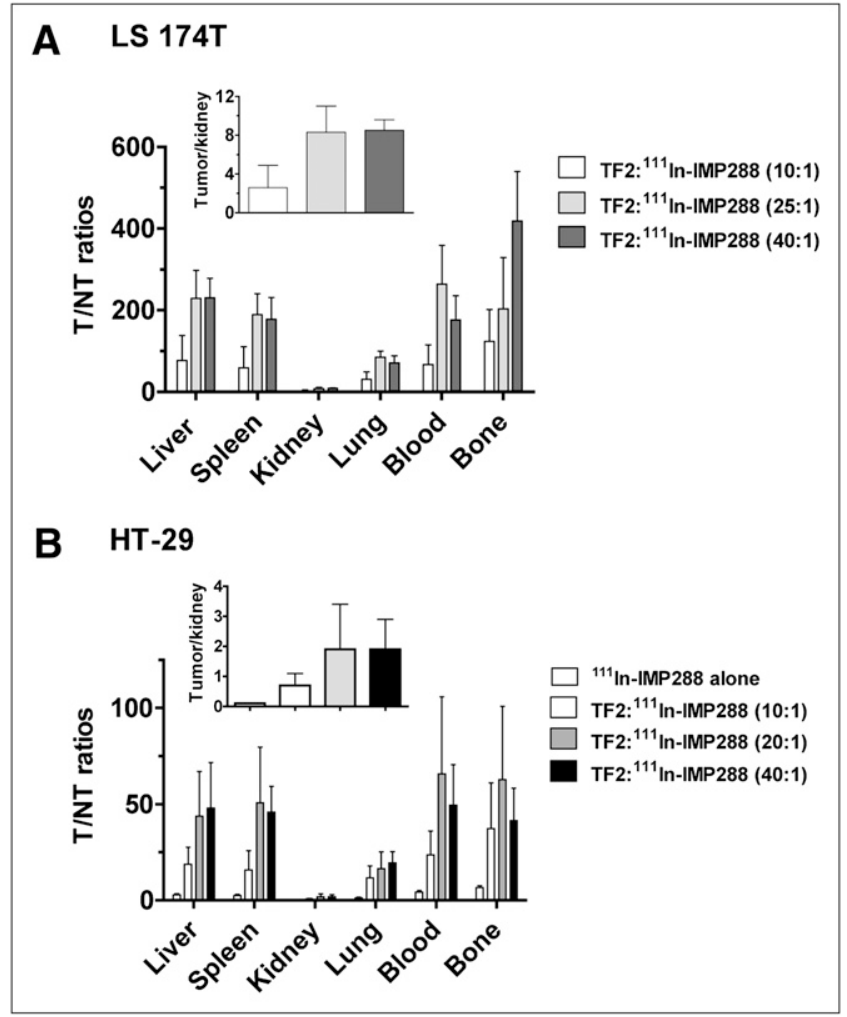

FIGURE 3. Tumor-to-nontumor ratios of ${ }^{111} \mathrm{In}$-IMP288 in mice bearing subcutaneous LS 174T (A) and HT-29 (B) human colon cancer xenografts. For pretargeting, TF2 anti-CEACAM5 bsmAb was given intravenously at 3 doses and then, $16 \mathrm{~h}$ later, ${ }^{111} \mathrm{In}-$ IMP288 $\left(2.53 \times 10^{-11} \mathrm{~mol}, 0.925 \mathrm{MBq}[25 \mu \mathrm{Ci}]\right)$ was given to all groups. For LS $174 \mathrm{~T}$, TF2 dose was $40 \mu \mathrm{g}\left(2.53 \times 10^{-10} \mathrm{~mol}\right)$ for $10: 1,100 \mu \mathrm{g}\left(6.34 \times 10^{-10} \mathrm{~mol}\right)$ for $25: 1$, and $160 \mu \mathrm{g}\left(1.01 \times 10^{-9}\right.$ mol) for 40:1 groups. For HT-29, TF2 doses were 40, 80, and $160 \mu \mathrm{g}$ for 10:1, 20:1, and 40:1 groups, respectively. Mice were necropsied $1.5 \mathrm{~h}$ after peptide injection. Inserts show tumor-to-kidney ratios. Tumor-to-kidney ratio for ${ }^{111} \mathrm{In}-\mathrm{IMP} 288$ (without TF2) was $0.08 \pm$ 0.03 . $\mathrm{T} / \mathrm{NT}=$ tumor to nontumor.

somewhat higher renal uptake for the ${ }^{111}$ In-IMP288 $(P=$ $0.04)$.

HT-29 accretion in the TF2- ${ }^{68} \mathrm{Ga}$-IMP288 pretargeted group was $8.6 \pm 1.3 \% \mathrm{ID} / \mathrm{g}(0.20 \pm 0.03 \% \mathrm{ID} / \mathrm{g}$ with ${ }^{68} \mathrm{Ga}$-IMP-288 alone). Tumor-to-nontumor ratios were again favorable (e.g., tumor-to-liver, tumor-to-spleen, tumor-tokidney, and tumor-to-blood ratios were $27 \pm 11,22 \pm 13$, $2.3 \pm 0.3$, and $28 \pm 9$, respectively) (Fig. 4). Tumor-to-liver, tumor-to-blood, and tumor-to-kidney ratios were $1.3 \pm 0.1$, $1.6 \pm 0.3$ and $0.065 \pm 0.003$, respectively, for ${ }^{68} \mathrm{Ga}$-IMP288 alone.

\section{DISCUSSION}

The short half-life of ${ }^{68} \mathrm{Ga}$ is matched well for rapidly clearing molecules, cost, procedural simplicity, and the ability to prepare products at high specific activities, contributing to its appeal for PET.

Our ${ }^{68} \mathrm{Ga}$-IMP288 labeling experience was favorable. The generator performed according to the manufacturer's specifications, with high elution efficiency remaining at approx-

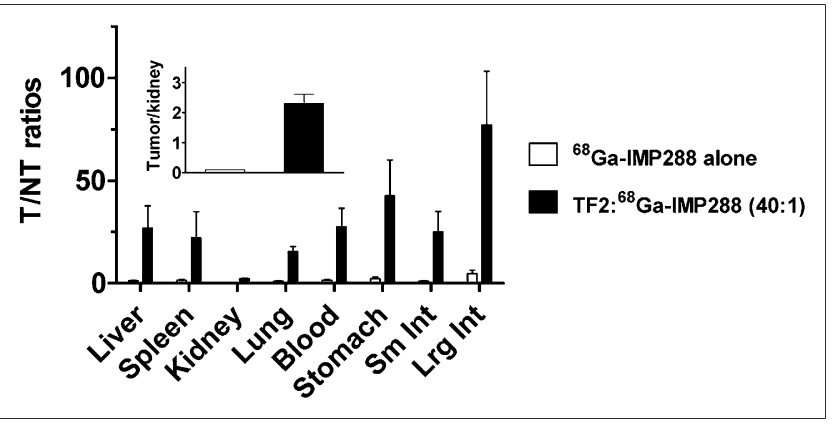

FIGURE 4. Tumor-to-nontumor ratios in nude mice bearing subcutaneous HT-29 human colon cancer xenografts (\%ID/g). Mice $(n=5)$ were given TF2 $\left(160 \mu \mathrm{g}, 1.01 \times 10^{-9} \mathrm{~mol}\right)$ intravenously, and after $16 \mathrm{~h}{ }^{68} \mathrm{Ga}-\mathrm{IMP} 288\left(2.53 \times 10^{-11} \mathrm{~mol}, 11.1 \mathrm{MBq}[300\right.$ $\mu \mathrm{Ci}$ ) was given intravenously. Another group received the same ${ }^{68} \mathrm{Ga}-I M P 288$ alone (no bsmAb). Specific activity of purified ${ }^{68} \mathrm{Ga}-$ IMP288 was $0.516 \mathrm{GBq} / \mathrm{nmol}$, and it was prepared with ascorbic acid. Mice were necropsied $1 \mathrm{~h}$ after peptide injection. Lrg Int $=$ large intestine; $\mathrm{Sm}$ Int = small intestine; T/NT = tumor-to-nontumor.

imately $1 \mathrm{y}$ after calibration (98 elutions). Isolating the peak amount of radioactivity in a $1.0-\mathrm{mL}$ fraction minimized the total elution volume. A more concentrated form was not required for successful radiolabeling. Ascorbic acid added during the radiolabeling procedure appeared to enhance recovery without altering the $\mathrm{pH}$, but we also routinely added it to the final product, which was stable for $2 \mathrm{~h}$.

${ }^{111} \mathrm{In}-,{ }^{90} \mathrm{Y}-$, and ${ }^{177} \mathrm{Lu}-\mathrm{IMP} 288$ have been prepared without purification, but ${ }^{68} \mathrm{Ga}-\mathrm{IMP} 288$ required HLB purification. Purification removed unwanted forms of ${ }^{68} \mathrm{Ga}^{3+}$, but it also removed ${ }^{68} \mathrm{Ge}$. Because gallium exists in various forms based on the $\mathrm{pH}$ and concentration (16), our goal was to retain the $\mathrm{pH}$ near 3.0, which is lower than most other ${ }^{68} \mathrm{Ga}$-DOTApeptides $(6,10,17-19)$. For example, Bauwens et al. found labeling efficiencies or more than $90 \%$ for ${ }^{68} \mathrm{Ga}$-DOTATOC using $1 \mathrm{M}$ HEPES, $\mathrm{pH} 3.75$, whereas with $0.5 \mathrm{M}$ sodium succinate, $\mathrm{pH}$ approximately 4.0, labeling efficiencies suffered when $10 \mu \mathrm{g}$ of the peptide was used (19). IMP288 labeling was always performed with less than $10 \mu \mathrm{g}$, and at pH 3.7 and 4.6, recovery from analytic RP-HPLC was low, but better recoveries were possible at the lower $\mathrm{pH}$.

Because unbound forms of ${ }^{68} \mathrm{Ga}^{3+}$ can be difficult to quantify, and to ensure ${ }^{68} \mathrm{Ga}$ was retained sufficiently by DOTA-IMP288, we repeatedly administered randomly selected products into mice. Hepatic and splenic uptake was reduced substantially by HLB purification, but even then it was somewhat higher than with ${ }^{111}$ In-IMP288, suggesting there may be a small amount of transchelation. A similar observation was reported, in a comparison study in rats, in which ${ }^{68} \mathrm{Ga}$-DOTATOC showed higher uptake in the liver than did ${ }^{111}$ In-DOTATOC (6).

\section{CONCLUSION}

${ }^{68} \mathrm{Ga}$-IMP288 specific activities as high as $0.84 \mathrm{GBq} / \mathrm{nmol}$ (i.e., starting specific activity, $1.776 \mathrm{GBq} / \mathrm{nmol}$ ) were achieved without any tedious handling of ${ }^{68} \mathrm{Ga} \cdot{ }^{68} \mathrm{Ga}$-IMP288 had excellent tumor localization properties in a bsmAb pretargeting setting and is easily and conveniently prepared, but a 
final purification procedure using an HLB reversed-phase cartridge is necessary to remove unwanted unbound ${ }^{68} \mathrm{Ga}^{3+}$ forms. Acceptable products could be prepared over a 1-y period from the generator's calibration date.

\section{ACKNOWLEDGMENTS}

This article is dedicated to the memory of Prof. Thomas M. Behr, who spent an important time in his short but productive career working at our center, before returning to Germany to become the youngest director of an academic nuclear medicine department. We thank Ali Mostafa, Tom Jackson, Dion Yeldell, and Jayson Jebsen for their technical assistance. William J. McBride, Edmund A. Rossi, ChienHsing Chang, and David M. Goldenberg are employed or have a financial interest in Immunomedics, Inc., or IBC Pharmaceuticals, Inc. This study was supported in part by NCI grant 2R44CA123985 and NJ CCR grant 10-8-CCREO.

\section{REFERENCES}

1. Ambrosini V, Campana D, Bodei L, et al. ${ }^{68} \mathrm{Ga}$-DOTANOC PET/CT clinical impact in patients with neuroendocrine tumors. J Nucl Med. 2010;51:669-673.

2. Ambrosini V, Castellucci P, Rubello D, et al. ${ }^{68}$ Ga-DOTA-NOC: a new PET tracer for evaluating patients with bronchial carcinoid. Nucl Med Commun. 2009;30:281-286.

3. Ambrosini V, Marzola MC, Rubello D, Fanti S. ${ }^{68} \mathrm{Ga}$-somatostatin analogues PET and ${ }^{18}$ F-DOPA PET in medullary thyroid carcinoma. Eur J Nucl Med Mol Imaging. 2010;37:46-48.

4. Banerjee SR, Pullambhatla M, Byun Y, et al. ${ }^{68} \mathrm{Ga}$-labeled inhibitors of prostatespecific membrane antigen (PSMA) for imaging prostate cancer. J Med Chem. 2010;53:5333-5341.

5. Baum RP, Prasad V, Muller D, et al. Molecular imaging of HER2-expressing malignant tumors in breast cancer patients using synthetic ${ }^{111} \mathrm{In}$ - or ${ }^{68} \mathrm{Ga}$-labeled affibody molecules. J Nucl Med. 2010;51:892-897.
6. Breeman WA, de Jong $\mathrm{M}$, de Blois E, Bernard BF, Konijnenberg M, Krenning EP. Radiolabelling DOTA-peptides with ${ }^{68} \mathrm{Ga}$. Eur J Nucl Med Mol Imaging. 2005;32:478-485.

7. Henze M, Schuhmacher J, Hipp P, et al. PET imaging of somatostatin receptors using ${ }^{68} \mathrm{Ga}$-DOTA-D-Phe1-Tyr3-octreotide: first results in patients with meningiomas. J Nucl Med. 2001;42:1053-1056.

8. Hoigebazar L, Jeong JM, Choi SY, et al. Synthesis and characterization of nitroimidazole derivatives for ${ }^{68} \mathrm{Ga}$-labeling and testing in tumor xenografted mice. J Med Chem. 2010;53:6378-6385.

9. Maecke HR, Hofmann M, Haberkorn U. ${ }^{68} \mathrm{Ga}$-labeled peptides in tumor imaging. J Nucl Med. 2005;46(suppl 1):172S-178S.

10. Meyer GJ, Macke H, Schuhmacher J, Knapp WH, Hofmann M. ${ }^{68}$ Ga-labelled DOTA-derivatised peptide ligands. Eur J Nucl Med Mol Imaging. 2004;31:10971104.

11. Tolmachev V, Velikyan I, Sandstrom M, Orlova AA. HER2-binding Affibody molecule labelled with ${ }^{68} \mathrm{Ga}$ for PET imaging: direct in vivo comparison with the ${ }^{111}$ In-labelled analogue. Eur J Nucl Med Mol Imaging. 2010;37:13561367.

12. McBride WJ, Zanzonico P, Sharkey RM, et al. Bispecific antibody pretargeting PET (immunoPET) with an ${ }^{124}$ I-labeled hapten-peptide. J Nucl Med. 2006;47: 1678-1688.

13. Schoffelen R, Sharkey RM, Goldenberg D, et al. Pretargeted immuno-positron emission tomography imaging of carcinoembryonic antigen-expressing tumors with a bispecific antibody and a ${ }^{68} \mathrm{Ga}$ - and ${ }^{18} \mathrm{~F}$-labeled hapten peptide in mice with human tumor xenografts. Mol Cancer Ther. 2010;9:1019-1027.

14. Sharkey RM, Karacay H, Vallabhajosula S, et al. Metastatic human colonic carcinoma: molecular imaging with pretargeted SPECT and PET in a mouse model. Radiology. 2008;246:497-507.

15. Rossi EA, Goldenberg DM, Cardillo TM, McBride WJ, Sharkey RM, Chang CH. Stably tethered multifunctional structures of defined composition made by the dock and lock method for use in cancer targeting. Proc Natl Acad Sci USA. 2006;103:6841-6846.

16. Green MA, Welch MJ. Gallium radiopharmaceutical chemistry. Int J Rad Appl Instrum B. 1989;16:435-448.

17. Velikyan I, Beyer GJ, Bergstrom-Pettermann E, Johansen P, Bergstrom M, Langstrom B. The importance of high specific radioactivity in the performance of ${ }^{68}$ Ga-labeled peptide. Nucl Med Biol. 2008;35:529-536.

18. Velikyan I, Maecke H, Langstrom B. Convenient preparation of ${ }^{68} \mathrm{Ga}$-based PET-radiopharmaceuticals at room temperature. Bioconjug Chem. 2008;19:569573.

19. Bauwens M, Chekol R, Vanbilloen H, Bormans G, Verbruggen A. Optimal buffer choice of the radiosynthesis of ${ }^{68} \mathrm{Ga}$-DOTATOC for clinical application. Nucl Med Commun. 2010;31:753-758. 